\title{
Genetic variants of uncoupling proteins-2 and -3 in relation to maximal oxygen uptake in different sports
}

\author{
Joanna Holdys ${ }^{1}$, Piotr Gronek ${ }^{\boxplus}$, Jakub Kryściak ${ }^{1}$ and Daniel Stanisławski \\ 'Department of Physiology, Faculty of Physical Education, Sport and Rehabilitation, The Eugeniusz Piasecki University School of Physical Educa- \\ tion, Poznań, Poland; ${ }^{2}$ Computer Laboratory of the Faculty of Animal Breeding and Biology, Poznań University of Life Sciences, Poznań, Poland
}

\begin{abstract}
Uncoupling proteins 2 and 3 (UCP2 and UCP3) as mitochondrial electron transporters are involved in regulation of ATP production and energy dissipation as heat. Energy efficiency plays an important role in physical performance, especially in aerobic fitness. The aim of this study was to examine the association between maximal oxygen uptake and genetic variants of the UCP2 and UCP3 genes. The studies were carried out in a group of 154 men and 85 women, professional athletes representing various sports and fitness levels and students of the University of Physical Education in Poznań. Physiological and molecular procedures were used, i.e. direct measurement of maximum oxygen uptake $\left(\mathrm{VO}_{2 \max }\right)$ and analysis of an insertion/deletion (I/D) polymorphism in the $3^{\prime}$ untranslated region of exon 8 of the UCP2 gene and a $C>T$ substitution in exon 5 (Y210Y) of the UCP3 gene. No statistically significant associations were found, only certain trends. Insertion allele (I) of the I/D UCP2 and the T allele of the UCP3 gene were favourable in obtaining higher $\mathrm{VO}_{2 \max }$ level and might be considered as endurance-related alleles.
\end{abstract}

Key words: UCP2, UCP3, athletic performance, genetic polymorphism, energy efficiency

Received: 28 September, 2012; revised: 15 December, 2012 accepted: 18 February, 2013; available on-line: 15 March, 2013

\section{INTRODUCTION}

Physical performance is acomplex phenotype influenced by both environmental and genetic factors. Great attention is paid to searching genes underlying athletic performance and variants predisposing to certain sport disciplines (Bray et al., 2009; Lippi et al., 2010; Maciejewska-Karłowska 2013; Gronek et al., 2013, Sawczuk et al., 2013). Energy efficiency considerably contributes to physical performance, especially aerobic fitness. Genetic variations in uncoupling protein genes may affect energy metabolism and thus be of great importance for athlete status.

ATP is produced by energy coupling at the level of the electron transport chain in mitochondria. In adipose tissue, this coupling with ADP phosphorylation is only partial, because uncoupling proteins (UCPs) induce a proton leak, releasing the energy stored in ATP as heat. UCPs belong to the large family of mitochondrial anioncarrier proteins (MCAPs). Among the 5 tissue-specific UCP homologues, two may be important for physical fitness: UCP2, which is expressed e.g. in muscles, white adipose tissue, spleen, lungs, heart, kidneys, and the cen- tral nervous system; and UCP3, found in skeletal muscles and the heart (Fleury \& Sanchis, 1999; Tu et al., 1999).

The physiological role of UCP2 has not been explained unambiguously so far. Numerous studies of transgenic animals - knock-out mice and mice with overexpression of the UCP2 gene - showed that the most probable function of this protein is mild energy uncoupling, which accelerates metabolism and protects cells against damage by reducing the amount of reactive oxygen species (ROS). The UCP2 protein is supposed to be associated with lipid metabolism and energy balance (Fleury \& Sanchis, 1999; Bouchard et al., 1997), as well as regulation of insulin excretion by pancreatic cells and development of diabetes type 2 caused by obesity, but it does not affect body weight (Ježek, 2002; Krauss et al., 2005; Erlanson-Albertsson, 2003). Molecular analysis of the UCP2 gene has revealed its several polymorphic variants, correlated mostly with obesity, BMI, resting metabolic rate (Fleury \& Sanchis, 1999; Warden, 1999), metabolic syndrome (Rosmond et al., 2002), or susceptibility to diabetes type 2 (Esterbauer et al., 2001), but the results are ambiguous. Moreover, some UCP2 alleles are associated with a higher energy efficiency, which suggests that UPC2 affects energy expenditure during physical activity (Beumann et al., 2001; Kimm et al., 2002).

The UCP3 protein is found mostly in skeletal muscles, which are crucial for thermogenesis and energy metabolism (Boss et al., 2000). Research on overexpression of this gene in muscles has shown that body weight is lower than in control individuals, while in muscles of UCP3knockout mice the proton leak is reduced and the ATP/ ADP ratio is increased (Ježek, 1999). UCP3 not only plays a role in energy uncoupling, as indicated by homology with the UCP1 gene (Hesselink et al., 2003), but it might also facilitate the oxidation of fatty acids, as their membrane carrier (Krauss et al., 2005) and - like UCP2 - it protects muscle cells against ROS by lowering the potential of the mitochondrial membrane (Esteves \& Brand, 2005; Stuart et al., 2001). Molecular analysis of the UCP3 gene has revealed the presence of numerous polymorphisms (mostly single-nucleotide polymorphisms, SNPs) associated with obesity and diabetes type 2 (Urhammer et al., 1998; Argyropoulos et al., 1998). Research on the effect of strength training on UCP3 expression

e-mail: gronek@awf.poznan.pl

Abbreviations: bp base pair; HRV, heart rate variability; $E$, endurance; E-Sp-ST, endurance-speed-strength; I/D, insertion/deletion; MCAPs, mitochondrial anion-carrier proteins; PCR-RFLP, polymerase chain reaction-restriction fragment length polymorphism; ROS, reactive oxygen species; SNP, single nucleotide polymorphism; Sp-St, speed-strength; UCP2, uncoupling protein-2; UCP3, uncoupling protein-3; UTR, untranslated region; $\mathrm{VCO}_{2}$, carbon dioxide output; $\mathrm{VO}_{2}$, oxygen uptake; $\mathrm{VO}_{2 \max }$ maximal oxygen uptake. 
showed a decrease in UCP3 mRNA level in athletes and a negative correlation with $\mathrm{VO}_{2 \max }$ (Fleury \& Sanchis, 1999; Russel et al., 2002). Regular physical exercise or strength training decrease UCP3 gene expression and the level of the protein itself in mitochondria, and this may increase energy efficiency in athletes (Fleury \& Sanchis, 1999; Schrauwen et al., 2005).

Other studies of UCP3 and UCP2 gene expression suggest that both proteins play a role in the regulation of lipid metabolism as an energy substrate in skeletal muscles. Increased expression of these genes was recorded in slim and obese people during fasting and association between UCP2 and UCP3 mRNA expression and lipid metabolism in the body was also observed (Fleury \& Sanchis, 1999; Boss et al., 2000). According to some studies, mitochondrial lipid metabolism regulation is the main ucp3 protein role. UCP3 in muscles is up regulated when fatty acid content in mitochondria increases, exceeding the capacity to oxidize them and down regulated when the fatty acids are low. Therefore, the ucp3 protein prevents mitochondrial oxidative damage caused by fatty acids accumulations and, in result, reduced mitochondrial function (Hoeks et al., 2006; Schrauwen et al., 2006; Nabben \& Hoeks, 2008). Some latest studies of UCP3 knock-out mice show no protective function of ucp3 protein (Nabblen et al., 2011), while other research indicate that UCP genes variability affects human longevity and may play a role in modulating aging, especially in muscles and nerves (Rose et al., 2011). A significant difference in hand grip strength - a measure of muscle aging — was observed in elderly people carrying different polymorphisms in the promoter region of the UCP3 gene which confirms the beneficial role of an efficient uncoupling process and ucp3 protein for muscle performance (Crocco et al., 2011).

Although lipid metabolism is crucial for aerobic capacity, so far only few studies have focused on the direct effects of polymorphisms of UCP genes on athlete performance (Bray et al., 2009). In this study, we analysed the association of the level of maximum oxygen uptake $\left(\mathrm{VO}_{2 \max }\right)$ with two polymorphisms: insertion/deletion $(\mathrm{I} / \mathrm{D})$ in exon 8 of the UCP2 gene and $\mathrm{C}>\mathrm{T}$ substitution in exon $5(630 \mathrm{C}>\mathrm{T}$; Y $210 \mathrm{Y})$ of the UCP3 gene.

\section{MATERIALS AND METHODS}

Study group. Studies were carried out on a group of professional athletes training in various sport disciplines, representing different sports classes, including representatives of Polish national teams and students of the University School of Physical Education in Poznań, all actively practicing sports, as well as those less active. The study was approved by the Poznan University of Medical Sciences Bioethics Committee, Poland, No 1060/05. Participants were informed about the aim and dangers of the analysis and each signed a written consent.

The group of 239 Caucasians (154 men and 85 women) aged 18-26 years was subjected to physiological and genetic analyses. All statistical analyses were performed separately for men and women.

In order to verify the effects of the analysed gene polymorphisms on maximal oxygen consumption, depending on the level of physical activity, the participants of this study were then divided into a group of athletes (119 men and 37 women) and those who did not train in any sports ( 35 men and 48 women). Additionally, athletes were then subdivided into three subgroups classified by the type of exercise metabolism predominating in the discipline they practice: (i) speed and strength disciplines (disciplines with predominance of anaerobic energy metabolism) were denoted as Sp-St, (ii) endurance-speedstrength disciplines (disciplines requiring both anaerobic and aerobic energy resources) were denoted as E-Sp-St, and (iii) endurance disciplines (those with predominating aerobic energy metabolism) were denoted as E. The division of sport disciplines was based on the classification system developed by Bellotti et al. (1978). The $\mathrm{Sp}-\mathrm{St}$ subgroup contained individuals training in shortdistance running, long jump, high jump, discuss throw, the E-Sp-St subgroup contained of individuals practising field hockey, tennis, rugby, football (soccer), volleyball, basketball, handball, boxing, kickboxing, canoeing, rowing, while the E subgroup included triathlonists, medium and long-distance runners, long-distance swimmers, race walkers, skiers, mountaineers.

$\mathbf{V O}_{2 \max }$ determination. Physiological analyses were conducted at the Laboratory of Functional Examinations at the University School of Physical Education in Poznań, certified by ISO 9001:2008 standards (no. 69178-2009-AQ-POL-RvA).

In order to determine the maximal oxygen uptake of the participants the direct method during exercise tests on a treadmill (Woodway, USA) was used. During each test, the composition of air inhaled and exhaled $\left(\mathrm{VO}_{2}\right.$, $\mathrm{VCO}_{2}$ ) was analysed by Oxycon Mobile spiroergometer (Jaeger, Germany) and the heart rate (HR) was monitored using a pulsometer (Polar, Finland). The exercise tests were carried out on a treadmill with increasing load, starting from a running speed of $8 \mathrm{~km} / \mathrm{h}$, increasing the load by $2 \mathrm{~km} / \mathrm{h}$ every $3 \mathrm{~min}$, until the moment of maximum individual load was reached.

Genotyping. Genetic analyses were conducted at the Laboratory of Genetic Analyses at the University School of Physical Education in Poznań, certified by ISO 9001:2008 standards (no. 69178-2009-AQ-POL-RvA).

DNA for genetic analyses was isolated from $5 \mathrm{ml}$ of peripheral blood collected from the participants onto anticoagulant (EDTA). DNA isolation was performed using the guanidine isothiocyanate (GTC, Sigma) method. The I/D polymorphism in exon 8 of UCP2 gene was genotyped by a polymerase chain reaction (PCR). DNA was amplified in a volume of $20 \mu \mathrm{l}$. Genomic DNA from each examined individual was placed in a separate test tube in the amount of $4 \mu \mathrm{l}(200 \mathrm{ng})$ and $16 \mu \mathrm{l}$ reaction mixture was added, containing $50 \mathrm{mM} \mathrm{KCl}, 10 \mathrm{mM}$ Tris/ $\mathrm{HCl}$ (pH 8.3), $1.5 \mathrm{mM} \mathrm{MgCl}, 0.25 \mathrm{mM}$ dNTP, 7.5 pmol each primer and 0.5 unit of Taq polymerase (Fermentas Life Sciences, Lithuania). The primers sequence was: Forward — CAg TgA ggg AAg Tgg gAg g and Reverse - ggg gCA ggA CgA AgA TTC (Walder et al., 1998). The 35 cycle reaction was run in a Biometra Tpersonal thermocycler. The cycle comprised initial denaturation at $95^{\circ} \mathrm{C}$ for 10 min., denaturation at $95^{\circ} \mathrm{C}-$ $30 \mathrm{~s}$, annealing at $55^{\circ} \mathrm{C}-30 \mathrm{~s}$, synthesis at $72^{\circ} \mathrm{C}-30 \mathrm{~s}$ and final synthesis at $72^{\circ} \mathrm{C}$ for $10 \mathrm{~min}$. PCR products 301 base pairs (bp) and 256 bp long were separated on a $2 \%$ agarose gel. Electrophoresis was run at $100 \mathrm{~V}$ for 30 min in Biometra agagel mini horizontal apparatus (Germany). The results were visualized on a UV transilluminator with $2 \mu \mathrm{l}$ of ethidium bromide $(5 \mathrm{mg} / \mathrm{ml})$.

Substitution $\mathrm{C}>\mathrm{T}$ in exon 5 of UCP3 gene was genotyped by PCR-RFLP method with RsaI enzyme. DNA was amplified in a volume of $25 \mu \mathrm{l}$. Genomic DNA from each examined individual was placed in a separate test tube in the amount of $4 \mu \mathrm{l}(200 \mathrm{ng})$ and $21 \mu \mathrm{l} \mathrm{reac}-$ tion mixture was added, containing $50 \mathrm{mM} \mathrm{KCl}, 10 \mathrm{mM}$ Tris/ $\mathrm{HCl}$ (pH 8.3), $1.5 \mathrm{mM} \mathrm{MgCl}, 0.25 \mathrm{mM}$ dNTP, 7.5 
Table 1. Descriptive statistics and comparative analysis of maximal oxygen uptake $\left(\mathrm{VO}_{2 \max } \mathrm{in} \mathrm{ml} / \mathrm{kg} \cdot \mathrm{min}^{-1}\right)$ between genotypes of the I/D UCP2 gene polymorphism.

\begin{tabular}{|c|c|c|c|c|c|c|c|c|c|c|c|c|c|c|c|}
\hline UCP2 & DD & & & & & ID & & & & & II & & & & \\
\hline Sex & $\mathrm{N}$ & $\bar{X}$ & SD & Min & Max & $\mathrm{N}$ & $\bar{X}$ & SD & Min & Max & $\mathrm{N}$ & $\bar{X}$ & $S D$ & Min & Max \\
\hline $\mathrm{F}$ & 42 & 45.65 & 6.14 & 32.30 & 59.00 & 36 & 45.66 & 7.18 & 30.60 & 59.80 & 7 & 45.07 & 7.60 & 35.00 & 54.80 \\
\hline M & 72 & $54.01^{\mathrm{a}}$ & 6.20 & 40.30 & 79.00 & 70 & 55.60 & 7.32 & 42.30 & 76.80 & 12 & $59.07^{a}$ & 9.04 & 49.70 & 74.90 \\
\hline
\end{tabular}

Analysis of variance did not show statistically significant differences between mean values of recorded maximal oxygen uptake in groups represented by DD, ID, II genotypes. a, difference observed between DD and II genotypes at $p$ value 0.052 in males.

pmol each primer and 0.5 unit of Taq polymerase. The primers sequence was: Forward - TCA Agg AgA AgC TgC TggG AgT, Reverse — TAC TAg gCA CTg CT'T CTC TCT CTg (Lanouette et al., 2002). The 40 cycle reaction was run in a Biometra T-personal thermocycler. The cycle comprised initial denaturation at $95^{\circ} \mathrm{C}$ for 10 min, denaturation at $95^{\circ} \mathrm{C}-30 \mathrm{~s}$, annealing at $53^{\circ} \mathrm{C}$ - $30 \mathrm{~s}$, synthesis at $72^{\circ} \mathrm{C}-30 \mathrm{~s}$ and final synthesis at $72^{\circ} \mathrm{C}$ for $10 \mathrm{~min}$. PCR products $130 \mathrm{bp}$ long were subsequently digested with $\mathrm{RsaI}$ restriction endonuclease in conditions recommended by the supplier (Fermentas Life Sciences, Lithuania). The digested products were then electrophoresed in a 10\% polyacrylamide gel at current intensity of $70 \mathrm{~V}$ for 16 hours. Results were visualized by silver staining.

Statistical analysis. Statistical calculations were performed at the Computer Laboratory of the Faculty of Animal Breeding and Biology at the Poznan University of Life Sciences, with the use of SAS statistical software ver. 9.1 (USA).

The consistency of the maximal oxygen uptake values and genotype distribution fit to the Hardy-Weinberg principle were verified with the $\chi^{2}$ test. The Bartlett test was performed to determine the homogeneity of variance. The association between analysed polymorphisms and maximal oxygen uptake $\left(\mathrm{VO}_{2} \mathrm{max}\right)$ was verified using the ANOVA one-way analysis of variance - the parametric test $t$.

\section{RESULTS}

In the experimental group normal distribution of the investigated parameter was confirmed in the $\chi^{2}$ test. The frequency of UCP2 and UCP3 genotypes was found within genetic equilibrium $\left(\chi_{\text {tab; } n-1=2, \alpha=0.05}^{2}=5.991\right.$ $>\chi^{2}$ calc. $=0.6835$ for UCP2 and $\chi^{2}$ calc. $=0.0440$ for $U C P 3)$. Descriptive statistics and the comparative analysis of maximal oxygen uptake recorded for individual polymorphic variants of the UCP2 and UCP3 gene are presented in Table 1 and 2, respectively. The ANOVA t-test revealed no statistically significant differences between mean values of maximal oxygen uptake observed in the three groups with different genotypes.

Further analysis of the experimental group divided into athletes and non-athletes and athletes representing disciplines with predominance of distinct energy metabolism showed no statistically significant difference between genotypes and mean values of maximal oxygen uptake. However, certain trends were observed. Concerning the UCP2 gene, higher $\mathrm{VO}_{2 \max }$ values were reached by men with II genotype in both groups: athletes and non-athletes. In females no such difference was observed. Further division of the athlete group revealed that in male and female endurance athletes I allele was favourable in obtaining higher $\mathrm{VO}_{2 \max }$ level, in contrary to those training speed and power-oriented or predominating in anaerobic metabolism disciplines, who reached higher $\mathrm{VO}_{2 \max }$ when they had at least one D allele. As for UCP3 gene, there were no significant differences in mean values of maximal oxygen uptake between genotypes in the nonathlete and athlete groups. Detailed division of the athlete group showed that the $\mathrm{T}$ allele was more favourable in obtaining higher $\mathrm{VO}_{2 \max }$ level in the endurance male athlete subgroup and all female subgroups, regardless the type of predominating energy metabolism. Male subgroups of speed-strength disciplines and those involving mixed muscle energy metabolism tended to have higher $\mathrm{VO}_{2 \max }$ level when carrying at least one $\mathrm{C}$ allele.

\section{DISCUSSION}

The most promising gene polymorphisms of uncoupling proteins UCP2 and UCP3 were selected for this study because of the significant role of energy metabolism in physical performance. The 3'-untranslated region (UTR) I/D polymorphism in UCP2 exon 8 and $\mathrm{C}>\mathrm{T}$ substitution in UCP3 exon 5 have not been associated with $\mathrm{VO}_{2 \max }$ so far but their participation in energy uncoupling during oxidative phosphorylation would suggest their effect on physical fitness. The more effective en-

Table 2. Descriptive statistics and comparative analysis of maximal oxygen uptake $\left(\mathrm{VO}_{2} \mathrm{max} \mathrm{in} \mathrm{ml} / \mathrm{kg}^{\mathrm{min}} \mathrm{m}^{-1}\right)$ between genotypes of $\mathrm{T}>\mathrm{C}$ polymorphism in exon 5 of UCP3 gene.

\begin{tabular}{|c|c|c|c|c|c|c|c|c|c|c|c|c|c|c|c|}
\hline UCP3 & $\pi$ & & & & & $\mathrm{TC}$ & & & & & $\mathrm{CC}$ & & & & \\
\hline Sex & $\mathrm{N}$ & $\bar{X}$ & SD & Min & Max & $N$ & $\bar{X}$ & SD & Min & Max & $\mathrm{N}$ & $\bar{X}$ & SD & Min & Max \\
\hline$F$ & 23 & $47.68^{a}$ & 5.99 & 35.00 & 59.80 & 45 & 45.68 & 6.67 & 31.30 & 59.00 & 17 & $42.62^{a}$ & 6.60 & 30.60 & 58.40 \\
\hline M & 48 & 55.42 & 7.51 & 41.10 & 74.90 & 75 & 54.95 & 7.54 & 40.30 & 79.00 & 31 & 55.08 & 5.04 & 46.80 & 69.80 \\
\hline
\end{tabular}

Analysis of variance did not show statistically significant differences between mean values of recorded maximal oxygen uptake in groups represented by TT. TC and CC genotypes. a, difference observed between TT and CC genotypes at $p$ value 0.056 in females. 
ergy coupling is, the more ATP is produced and used during strenuous exercise. Energy uncoupling and dissipation as heat lowers the efficiency of muscles, although it also protects the tissue because of the diminished oxidative stress (a smaller amount of generated ROS). Participation of these proteins in lipid metabolism energy substrates for aerobic respiration - also suggests their possible effect on aerobic fitness (Wallace, 2005; Rosmond et al., 2002).

UCP2 gene polymorphisms have been considered so far in respect of their effect on obesity, resting metabolic rate, metabolic disorder, or diabetes (Tu et al., 1999; Warden, 1999; Rosmond et al., 2002). The results of those studies are ambiguous. I/D polymorphism in UCP2 exon 8 has not been associated so far with $\mathrm{VO}_{2 \mathrm{max}}$. In the present study, men with II genotype had higher $\mathrm{VO}_{2 \max }$ values than those with DD genotype. In the subgroup of endurance athletes, differences in mean $\mathrm{VO}_{2 \max }$ values reached nearly $10 \mathrm{ml} / \mathrm{kg}^{-1} \cdot \mathrm{min}^{-1}(58.81$ $\mathrm{ml} / \mathrm{kg}^{-1} \cdot \mathrm{min}^{-1}$ for DD versus $69.5 \mathrm{ml} / \mathrm{kg}^{-1} \cdot \mathrm{min}^{-1}$ for II). The number of individuals with II genotype was low in this study, but they tended to reach higher $\mathrm{VO}_{2 \max }$ values. A significant relationship between I/D polymorphism in UCP2 exon 8 of II genotype and the lowest daily energy expenditure as well as basal metabolic rate and lower BMI were noticed. Matsunaga et al. (2009) showed a significant relationship between II genotype and both high blood pressure and heart rate variability (HRV) in young healthy people. Those authors suggested a relationship between the I/D polymorphism of UCP2 and autonomous regulation of the circulatory system. The effect of the analysed UCP2 polymorphism on basal metabolic rate and control of the circulatory system may indicate a potential influence also on physical fitness.

For the UCP3 Rsal polymorphism (C>T), no significant differences were found between $\mathrm{VO}_{2 \max }$ and genotype. A nearly significant difference $(p=0.056)$ was observed between CC genotype, characterized by the lowest mean $\mathrm{VO}_{2} \max$, and T'T, with the highest $\mathrm{VO}_{2 \max }$ in women. Though there are small differences in $\mathrm{VO}_{2 \max }$ after division into subgroups based on the type of metabolism, genotype CC seems to have a positive effect on the level of $\mathrm{VO}_{2 \max }$ in non-athletes, speed and poweroriented athletes, as well as those practising disciplines involving mixed energy metabolism. In the endurance athlete group the TT genotype seems to be more favourable. There are some published reports on associations of different polymorphism in the UCP3 gene promoter (rs1800849) and aerobic fitness (Ahmetov et al., 2009; Otabe et al., 2000), but there are no reports on association of $\mathrm{C}>\mathrm{T}$ substitution (210Y210) in exon 5 with $\mathrm{VO}_{2}$ max. Indirect conclusions can be drawn from the available research on the effect of polymorphisms of the UCP3 gene on its expression (Fleury \& Sanchis, 1999) and lipid metabolism (Kimm et al., 2002; Lanouette et al., 2002; Damcott et al., 2004). The UCP3 polymorphism in exon $5(\mathrm{C}>\mathrm{T})$ is a silent substitution, which has no effect on protein function (Y210Y), however, it may be in linkage disequilibrium (Kimm et al., 2002; Damcott et al., 2004) with polymorphisms of another gene or located near UCP2, that could modify its expression or function. Kimm et al. (2002) observed a higher resting metabolic rate in people with the TT genotype than in CC individuals. Those authors hypothesized that the $\mathrm{C}$ allele may be associated with more economic energy metabolism. Damcott et al., (2004) found a correlation between $\mathrm{C}$ allele and higher total energy consumption but lower fat mass, free fatty mass, and BMI. According to other research, the $\mathrm{C}$ allele is a marker of higher UCP3 expres- sion (Fleury \& Sanchis, 1999). These results show that expression of the UCP3 gene is higher and fat mass is lower in people carrying the $\mathrm{C}$ allele, in spite of greater calorific intake. The lower fat mass and higher UCP3 expression in CC genotype individuals suggest that the excess calories are used as a source of energy, instead of being converted to and stored as adipose tissue (Damcott et al., 2004). Thus the presence of the $C$ allele should be favourable for aerobic metabolism. The generally higher values of $\mathrm{VO}_{2 \max }$ in $\mathrm{CC}$ genotype individuals in this study seem to confirm this hypothesis. However, in the endurance athlete group a higher level of $\mathrm{VO}_{2 \max }$ was obtained by TT genotype individuals. According to available data, endurance training results in a decrease of UCP3 gene expression in muscles and an increase in the produced amount of ATP and higher energy efficiency (Russel et al., 2002; Schrauwen et al., 2005). Additionally, over $50 \%$ increase in UCP3 mRNA transcription in muscles was observed in individuals carrying at least one copy of the T allele (Fleury \& Sanchis, 1999). Thus, our results seem to point at the $\mathrm{T}$ allele as a candidate marker of higher aerobic fitness level. However, further studies on larger endurance athlete groups, including other genetic variations in $U C P 2$ and $U C P 3$ genes and gene expression need to be conducted to confirm the influence of genetic polymorphisms in these genes on aerobic fitness. In conclusion, our research indicates favourable effect of I allele of the I/D polymorphism in exon 8 of the UCP2 gene and $\mathrm{T}$ allele of $\mathrm{C}>\mathrm{T}$ substitution in exon 5 (Y210Y) in UCP3 gene on obtaining higher levels of maximal oxygen uptake in endurance athletes. Our study was the first step to consider these polymorphisms as relevant for endurance athlete performance and further analysis should clarify whether they can be regarded as performance enhancing polymorphisms.

\section{Acknowledgments}

This project was performed done with internal financial support of the University School of Physical Education in Poznań, Poland.

The authors declare that they have no conflict of interest.

\section{Authors contributions}

All authors confirm that they have contributed to the intellectual content of this paper and have met the following requirements: (a) significant contributions to the conception and design, acquisition of data or analysis and interpretation of data; (b) drafting or revising the article for intellectual content; and (c) final approval of the published article.

\section{REFERENCES}

Ahmetov II, Williams AG, Popov DV et al. (2009) The combined impact of metabolic gene polymorphism on elite endurance athletes status and related phenotypes. Hum Gen 126: 751-761.

Argyropoulos G, Brown AM, Willi SM, Zhu J, He Y, Reitman M, et al. (1998) Effects of mutations in the human uncoupling protein 3 gene on the respiratory quotient and fat oxidation in severe obesity and type 2 diabetes. J Clin Invest 102: 1345-1351.

Bellotti P, Benzi G, Dal Monte A, Donati A, Matteucci E et al. (1978) Classificazione degli Sport e determinazione del mezzi di allenamento. Atleticastudi $3 / 4$.

Beumann B Schierning B, Toubro S, Bibby BM, Sorensen T, Dalgaard $\mathrm{L}$ et al., (2001) The association between the val/ala-55 polymorphism of the uncoupling protein 2 gene and exercise efficiency. Int J Obes Relat Metab Disord 4: 467-471.

Boss O, Hagen T, Lowell BB (2000) Uncoupling proteins 2 and 3: Potential regulators of mitochondrial energy metabolism. Diabetes 49: 143-156. 
Bouchard C, Perusse L, Chagnon YC, Warden C, Ricquier D et al. (1997) Linkage between markers in the vicinity of the uncoupling protein 2 gene and resting metabolic rate in humans. Hum Molec Genet 6: 1887-1889.

Bray MS, Hagberg JM, Pérusse L, Rankinen T, Roth SM, Wolfarth B, Bouchard C. (2009) The human gene map for performance and health-related fitness phenotypes: the 2006-2007 update. Med Sci Sports Exerc 41: 35-73.

Crocco P, Montesanto A, Passarino G, Rose G (2011) A common polymorphism in the UCP3 promoter influences hand grip strength in elderly people. Biogerontology 12: 265-71.

Damcott CM, Feingold E, Moffet SP, Barmada MM, Marshall JA, Hamman RF et al. (2004) Genetic variation in uncoupling protein 3 is associated with dietary intake and body composition in females. Metabolism 53: 458-464.

Erlanson-Albertsson C (2003) The role of uncoupling proteins in the regulation of metabolism. Acta Physiol Scand 178: 405-412.

Esterbauer H, Schneitler C, Oberkofler H, Ebenbichler C, Paulweber B, Sandhofer F et al. (2001) A common polymorphism in the promoter of UCP2 is associated with decreased risk of obesity in middle-aged humans. Nature Genet 28: 178-183.

Esteves TC, Brand MD (2005) The reactions catalysed by the mitochondrial uncoupling proteins UCP2 and UCP3. Biochim Biophys Acta 1709: 35-44.

Fleury C, Sanchis D (1999) The mitochondrial uncoupling protein-2: current status. Int J Biochem Cell Biol 31: 1261-1278.

Gronek P, Holdys J, Konarski J, Kryściak J, Wolc A (2013) ACE genotype in professional field hockey players. Trends Sport Sci 1: 38-42.

Hesselink MKC, Greenhaff PL, Constantin-Teodosiu D, Hultman E, Saris WHM, Nieuwlaat R et al. (2003) Increased uncoupling protein 3 content does not affect mitochondrial function in human skeletal muscle in vivo. J Clin Invest 111: 479-486.

Hoeks J, Hesselink MK, Schrauwen P (2006) Involvment of UCP3 in mild uncoupling and lipotoxicity. Exp Gerontol. 41: 658-662.

Ježek P (1999) Fatty acid interaction with mitochondrial uncoupling proteins. J Bioenerg Biomembr 31: 457-466.

Ježek P (2002) Possibile physiological role of mitochondria uncoupling proteins - UCP ${ }_{n}$. Int J Biochem Cell Biol 34: 1190-1206.

Kimm SY, Glynn NW, Aston CE, Damcott CM, Poehlman ET, Daniels SR et al. (2002) Racial differences in the relation between uncoupling protein genes and resting energy expenditure. Am J Clin Nutr 75: 714-719.

Krauss S, Zhang CY, Lowell BB (2005) The mitochondrial uncouplingprotein homologues. Nat Rev Mol Cell Biol 6: 248-261.

Lanouette Ch-M, Chagnon YC, Rice T, Pérusse L, Muzzin P, Giacobino J-P et al. (2002) Uncoupling protein 3 gene is associated with body composition changes with training in HERITAGE study. $J$ Appl Physiol 92: 1111-1118.

Lippi G, Longo UG, Maffulli N (2010) Genetics and sports. Br Med Bull 93: 27-47.

Maciejewska-Karłowska A (2013) Polymorphisms in the Peroxisome Proliferator-Activated Receptor genes: relevance for athletic performance Trends Sport Sci 1: 5-15.

Matsunaga T, Gu N, Yamazaki H, Tsuda M, Adachi T, Yasuda K, Moritani T et al. (2009) Association of UCP2 and UCP3 polymorphisms with heart rate variability in Japanese men. J Hypertens 27: 305-313.
Nabben M, Hoeks J (2008) Mitochondrial uncoupling protein 3 and its role in cardiac- and skeletal muscle metabolism. Physiol Behav 94: 259-269.

Nabben M, Shabalina IG, Moonen-Kornips E, van Beurden D, Cannon B, Schrauwen P, Nedergaard J, Hoeks J (2011) Uncoupled respiration, ROS production, acute lipotoxicity and oxidative damage in isolated skeletal muscle mitochondria from UCP3-ablated mice. Biochim Biophys Acta 1807: 1095-1105.

Otabe S, Clement K, Dina C, Pelloux V, Guy-Grand B, Froguel P et al. (2000) A genetic variation in the 5' flanking region of the UCP3 gene is associated with body mass index in humans in interaction with physical activity. Diabetologia 43: 245-249.

Rose G, Crocco P, De Rango F, Montesanto A, Passarino G (2011) Further support to the uncoupling-to-survive theory: the genetic variation of human UCP genes is associated with longevity. PLOS One 6: e29650. doi: 10.1371/journal.pone.0029650.

Rosmond R, Bouchard C, Björntorp P (2002) Lack of association between the uncoupling protein-2 Ala55Val gene polymorphism and phenotypic features of the Metabolic Syndrome. Biochim Biophys Acta 1588: 103-105.

Russell A, Wadley G, Snow R, Giacobino JP, Muzzin P, Garnham A et al. (2002) Slow component of $\mathrm{VO}_{2}$ kinetics: the effect of training status, fibre type, UCP3 $\mathrm{mRNA}$ and citrate synthase activity. Int $\mathrm{J}$ Obes Relat Metab Disord 26: 157-164.

Sawczuk M., Maciejewska-Karłowska A, Cięszczyk P (2013) A single nucleotide polymorphism rs553668 in $A D R A 2 A$ gene and Polish elite endurance athlete status. Trends Sport Sci 1: 32-37.

Schrauwen P, Hoeks J, Hesselink MK (2006) Putative function and physiological relevance of the mitochondrial uncoupling protein-3: involvement in fatty acid metabolism? Prog Lipid Res 45: 17-41.

Schrauwen P, Russell AP, Moonen-Kornips E et al. (2005) Effect of 2 weeks of endurance training on uncoupling protein 3 content in untrained human subjects. Acta Physiol Scand 183: 273-280.

Stuart JA, Cadenas S, Jekabsons MB, Roussel D, Brand MD et al. (2001) Mitochondrial proton leak and the uncoupling protein 1 homologues. Biochim Biophys Acta 1504: 144-158.

Tu N, Chen H, Winnikes U, Reinert I, Marmann G, Pirke KM et al. (1999) Structural organization and mutational analysis of the human uncoupling protein-2 (hUCP2) gene. Life Sci 64: 41-50.

Urhammer SA, Dalgaard LT, Sørensen TI, Tybjaerg-Hansen A, Echwald SM, Andersen T et al. (1998) Organisation of the coding exons and mutational screening of the uncoupling protein 3 gene in subjects with juvenile-onset obesity. Diabetologia 41: 241-244.

Walder K, Norman RA, Hanson RL, Schrauwen P, Neverova M, Jenkinson CP et al. (1998) Association between uncoupling protein polymorphisms (UCP2-UCP3) and energy metabolism/obesity in Pima Indians. Hum Mol Gen 7: 1431-1435.

Wallace DC (2005) The mitochondrial genome in human adaptive radiation and disease: on the road to therapeutics and performance enhancement. Gene 354: 169-180.

Warden C (1999) Genetics of uncoupling proteins in humans. Int J Obes Relat Metab Disord 23: S46-S48. 